\title{
Museiljus och TEATERljus
}

\section{Stefan Wiktorsson}

Det finns många likheter mellan ljussättning i teatrar och museer. På teatern arbetar vi ofta med ett scen - salong forrhallande. Publiken sitter på ett ställe och "utställningen " utspelar sig på ett annat.

På museet fungerar det ungefär lika fastän här går besökaren runt bland föremålen och "föreställningen " utvecklas $i$ takt med att varje besökare rör sig runt $i$ lokalernas iscensättningar, går från ett rum till ett annat. Det är i varje fall samma principer man arbetar med som ljussättare.

Det som påverkar vår upplevelse är förändringen av ljus, inte det statiska tillståndet. Om jag t ex vill skapa en känsla av kyla och mörker i ett rum, så är det inte säkert att ljuset $\mathrm{i}$ det rummet måste vara kallt eller blått eller att det ens måste vara mörkt, det kan vara lika effektivt att göra rummet man lämnar, extra ljust, extra varmt. Vi människor registrerar hela vår omvärld som en serie av förändringar. Det är nog därför det blir så fånigt när man försöker katalogisera ljusstyrkor och färger i absoluta objektiva tal, när allt är en fråga om relationer till annat, nyss upplevt.

Den enda principiella skillnaden mellan museiljus och teaterljus är nog att man på museet inte kan belysa föremålen lika starkt. Man måste noggrant följa de skilda normer som gäller för exponering av olika material. Däremot kan man ju använda alla möjliga tricks och knep för att få besökarna att uppleva exempelvis en akvarell som starkt belyst fastän ljusstyrkan i själva verket är mycket låg.
FÖRSTÖR INTE VARA KONSTSKATTER!

Allt ljus förstör. Ljus är strålning. Olika våglängder i ljuset förstör olika saker. Olika pigmentblandningar, olika material förtvinar och bleks under helt olika förutsättningar. De riktvärden som man bollar runt med på museerna, 50 lux för organiskt material, 130-180 lux för oljemålningar etc, är inga vetenskapliga siffror. De har kommit till utifrån: någon i England har tyckt att 50 lux borde vara den lägsta tänkbara nivå på ljuset för att besökarna klart ska kunna avläsa färg och form på ett föremål. Detta värde har enbart med perception att göra, om ens det. Modern psykologisk forskning pekar snarare på ett minsta värde omkring 200 lux om vi ska ta hänsyn till människor äldre än 70 år.

För att kunna visa ljuskänsliga föremål i våra museer bör man alltså sträva efter att ge dessa så låga stråldoser som möjligt av 
64 de förstörande våglängderna. I varje fall kan man ju se till att inte bestråla med rent UV-ljus eller med värmestrålning. Dessa typer av ljus är ändå inte synliga för oss människor.

\section{LJUSETS DYNAMIK}

Det mest spännande med museiljus och ljussättning är den dramatiska formen, ljusets dynamik. Ljuset måste framhäva, skulptera och göra utställningen i sin helhet intressant. Om man skulle belysa en utställning exakt och endast $\mathrm{i}$ enlighet med de normer som finns, så skulle resultatet bli tämligen ointressant. Alla föremål skulle skymta i ett svagt töcken, ett ljus utan vare sig egentlig riktning, definierad ljusstyrka, färg eller rörelse.

Elkonsulter arbetar ofta efter mätbara principer. Ett restaurangbord ska enligt normerna ha 500 lux, så att man kan se maten ordentligt samt att kyparen inte ska riskera att snubbla. En ljussättare skulle förmodligen med samma uppgift för ögonen ställa ut ett stearinljus på varje bord med motiveringen att det blir trevligare. Detta är nog också den avgörande skillnaden mellan elkonsulter och ljussättare.

Naturligtvis måste vi ha normer, de är själva förutsättningen för museiljussättning. Men uppfyllda normer kan aldrig ens bli en fingervisning om vilken grad av konstnärligt resultat som uppnåtts. Man måste tillfälligt kunna strunta $i$ alla luxvärden för att fritt kunna fantisera. Därefter kan man mäta och korrigera alla ljusnivåer enligt konstens alla regler. På så sätt tror jag att man skapar en väl fungerande dynamisk ljussättning inom normernas ram. Det är ofta möjligt att förändra, byta ut, flytta runt föremål för att få en spännande kom- bination av ljus och skugga, stämningar, former, färger, rumskomposition och ett samtidigt bevarande av föremålen.

\section{NELL WALDEN - FÖRESTÄLLNINGEN}

Landskrona museum. Invigd oktober 1986. Ljussättningsarbetet:

Hela utställningen påminner om teater. Den använder teaterns stora, spektakulära och i viss mån vulgära uttrycksmedel. Varje rum är en liten scen där vi besökare ser utställningen utifrån människan Nell Walden. Hennes liv och den enormt livliga konstepok som hon levde mitt i; futurismen, expressionismen, kubismen...

Jag tror inte alla tycker om det här subjektiva sättet att göra utställningar på. Det har heller aldrig varit vår tanke. Några älskar det och andra avskyr det. En sak är dock säker. Man går inte igenom utställningen utan att alls reagera.

Nell Walden sa: Man måste ständigt våga experimentera, alla experiment lyckas inte, men de måste ändå göras.

Nell Walden - utställningen gjordes i den andan.

Vi hade mycket roligt.

\section{Den färdiga utställningen}

Det är mycket svårt att i ord beskriva en ljussättning. Ofta gör man efterkonstruktioner, där även tillfälligheter presenteras som genialiska grepp. Jag ska i alla fall kortfattat försöka beskriva mina tankegångar runt varje rum $\mathrm{i}$ utställningen.

Om verkligheten mot förmodan inte skulle uppfylla sagan. Då är sagan sann.

\section{Entrén}

Vi möts av den starkt upplysta entrén. Portalen är utformad som ett dörrfoder 


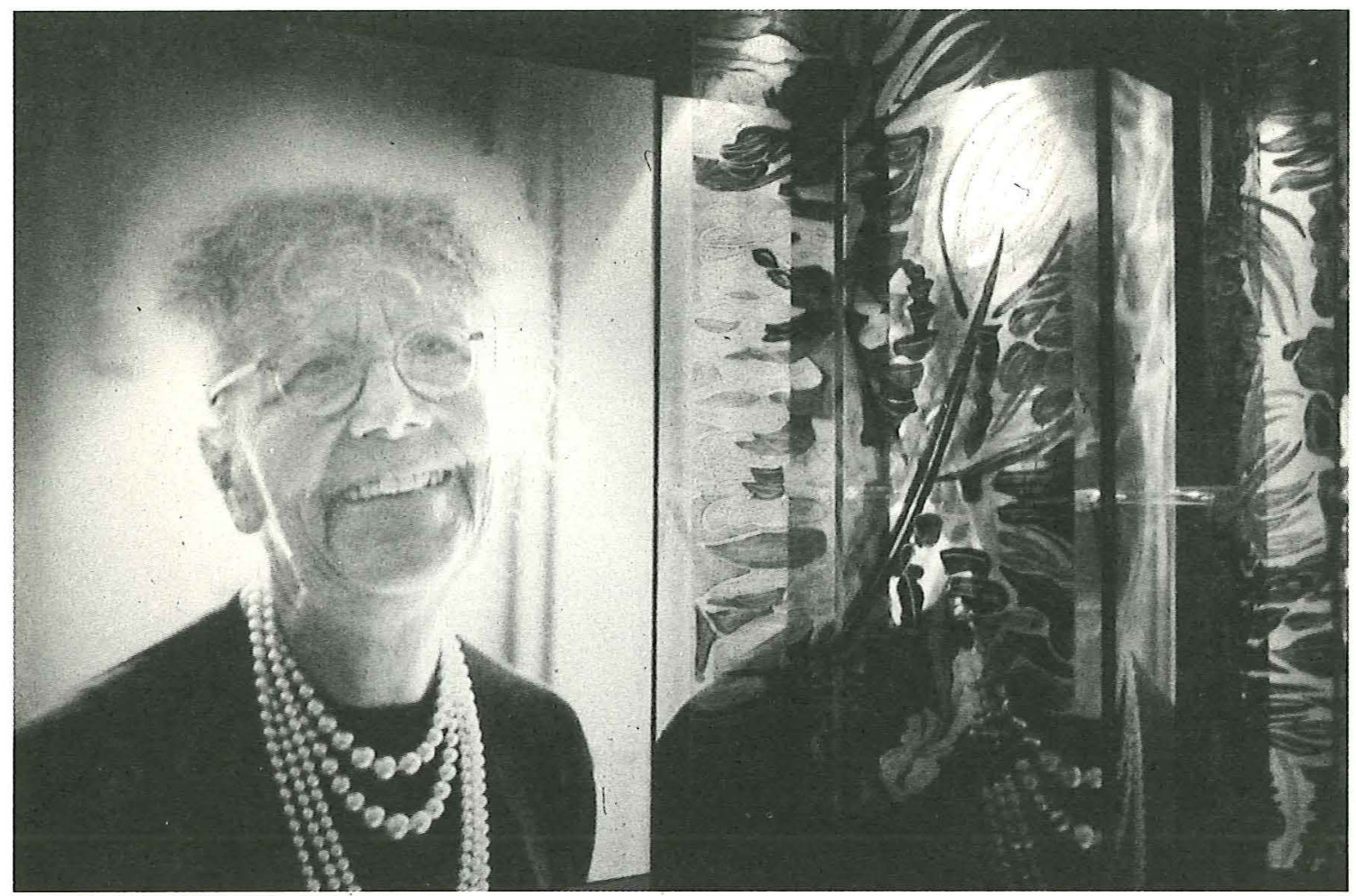

Nell Walden-utställningen Landskrona museum 1986. Direkt innanför entrén möts vi av en förstätkt färgkaskad $i$ rött och blätt. Kraftiga färger som belyser plexiglas som inramar ett porträtt i svartvitt av Nell Walden som gammal kvinna; en färgstark kvinna i händelsernas centrum. Foto: Landskrona museum.

målat helt i linje med Nell Waldens eget måleri, färgsprakande och livfullt. Själva utställningsentrén är nog det ljusaste partiet i hela utställningen. Detta främst för att dra till sig besökare, men också för att färgerna i måleriet ska få sin fulla lyster.

Från entrén faller sedan ljuset i styrka genom hela vandringen. Man märker först vid utställningens slut hur mörkt det i själva verket varit. Denna ljusuppläggning med långsamt fallande ljusstyrka är till för att besökarna ska hinna vänja sig vid svagare ljusnivåer, det vill säga vi kan bestråla föremålen mindre och mindre, utan att någon ska behöva uppleva rummen som mörka.

\section{Ungdomen}

Direkt innanför entrén möts vi av en förstärkt färgkaskad i rött och blått. Kraftiga färger som belyser plexiglas som inramar ett porträtt i svartvitt av Nell Walden som gammal kvinna. Det kan vara ganska riskabelt att i ljuset ha så kraftiga färger i början på en utställning. Det finns alltid en risk att man etablerar ett färgspråk som man sedan får svårt att konsekvent följa upp. För att undvika detta filtrerades det svartvita fotot i svagt blågrönt, en färg som förstärker det svartvita och ger färgerna runt omkring den extra lyster som krävdes. Bilden som presenteras för besökaren blir Nell Walden; en färgstark gammal kvinna i händelsernas centrum, som vi efter denna första presentation, kommer att följa från ungdomen vidare genom livet och konsten.

Detta första rum tar upp hennes bakgrund, kärleken, giftermålet. Miljön är ljus. Väggar och tak himmelsblå. Det hela ger associationer till ett gulligt flickrum.

Ljuset förstärker denna känsla. Ljuset är i detta rum är vitt (ofiltrerat), starkt och lyser endast på föremålen och på texterna. 
STEFAN WIKTORSSON

66

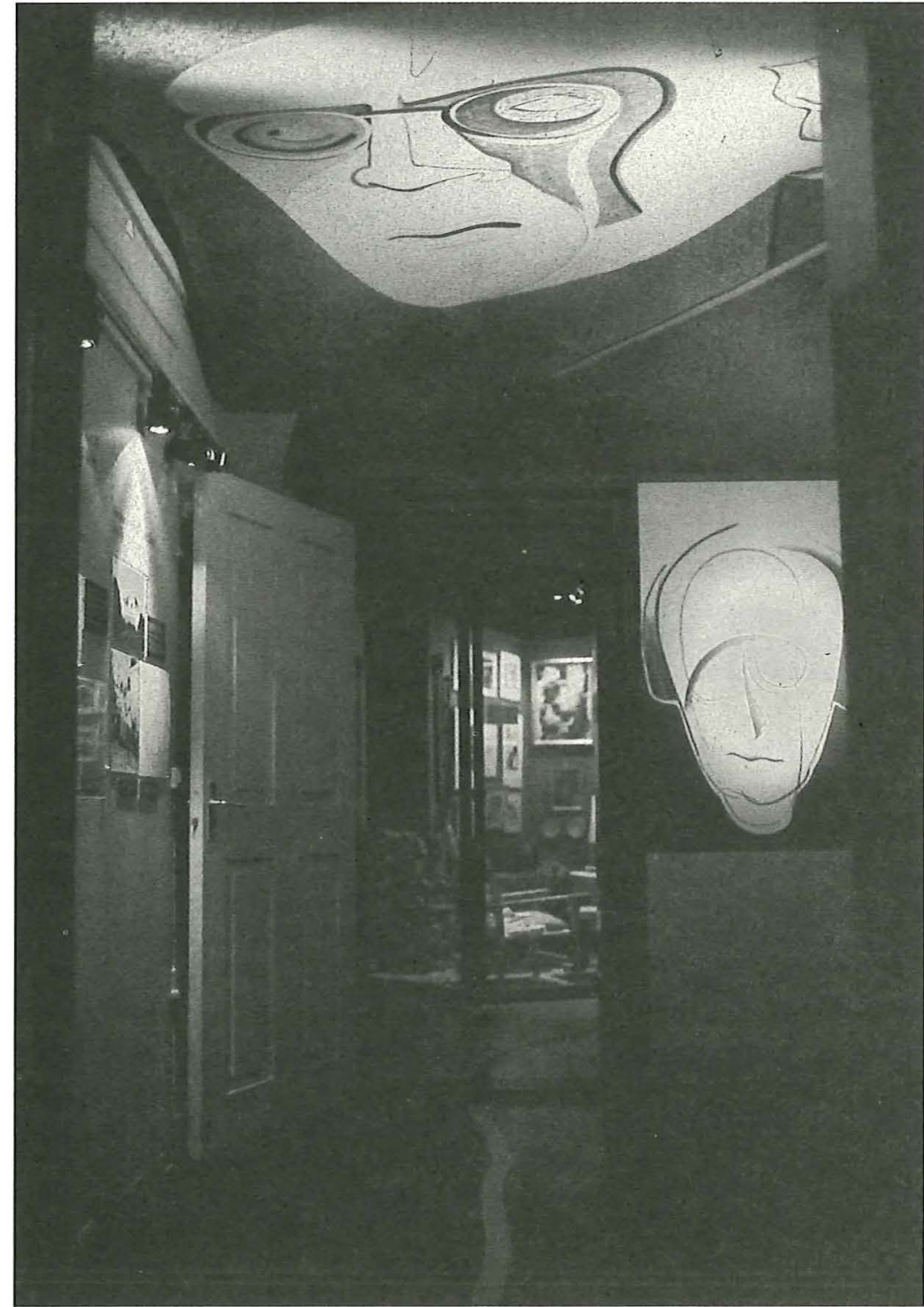

Nell Walden-utställningen Landskrona museum 1986. Foto: Landskrona museum.

För att detta inte skulle bli för tråkigt ligger det några ljusaccenter i rökrosa, en färg som jag tycker förstärker den borgerliga uppväxten och gör att hela rummet upplevs som ännu mer oskyldigt och barnsligt. Rosa passar också bra mot det ljusblå. Färgerna kompletterar varandra, gör rummet balanserat. 


\section{Berlin}

Nästa rum blir en kontrast. En inrökt cafémiljö från Berlin.

Ett nikotinfärgat ljus silar in genom det mjölkglasade taket. Allt det ungdomliga och friska från föregående rum är borta. Möjligtvis kan man i caféfönstret ana ett solljus som faller in på fönsterbrädan och genom gardinerna skymta en kallt belyst gatumiljö utanför.

Kyligt ljus faller också in från nästa rum. Dessa inslag av kyligare ljus perifert ökar känslan av värme och gemenskap i cafémiljön samtidigt som det gula inrökta betonar skillnaden från föregående rum.

\section{Futurism}

Det preussiska Berlin: Direkt utanför caféet möts vi av en starkt belyst gnistrande hjälm och en kall gatumiljö. Detta är anslaget till ett scenografiskt mycket fantasifullt uppbyggt rum. En jättetavla skjuter upp snett ur golvet. Den högra väggen, en presentation av Sturmtidskriften. Skrivmaskiner på stålbalkar skjuter ut ur väggen, där punktbelysta vita ark ger information. Övriga väggar innehåller texter och material som på ett eller annat sätt illustrerar resande, bl a två montrar med etnografika. Bildmässigt förstärks detta av ett expressionistiskt tåg som $\mathrm{i}$ iskall belysning virvlar fram diagonalt över taket.

Trots att detta rum innehåller så många föremål, av så många olika slag och så mycket information, blir upplevelsen en helhet, om än kaotisk.

Ljuset i detta rum är en slags komposition av varmt och kallt ljus. Sturm, etnografika, texter i varmt ljus. Tåg, hjälm, stadsbilder i kallt ljus. Vita accenter.

Rummet avslutas med den varmt belysta entréportalen till nästa rum.
Utställningslokalen

Scenografiskt är detta rum uppbyggt som en utställningslokal från tiden. Dagsljusinsläpp, filtrerat med reduktionsfilter och med tunna bomullsgardiner för. På väggarna hänger tavlor, där varje tavla har sin egen punktbelysning, skarpt skuren efter ramarna, från osynliga strålkastare, gömda i ett slags undertak. Miljön; utställningslokal, förstärks genom att fyra lampglober i taket lyser svagt blekgult. Upplevelsen av hela rummet accentueras av en nytillverkad futuristisk träskulptur och ett halvt piano som sticker ut ur väggen.

Ljuset är koncentrerat på dessa två föremål samt på tavlorna. Takgloberna gör att rummet som helhet upplevs som lugnt och harmoniskt. Som en utställningslokal.

\section{Dramatiskt rum}

Hervart Waldens död: Ett mycket dramatiskt litet rum med nygjorda målningar i färgerna rött och svart. Målningarna är mycket stora och täcker alla väggar samt tak.

Belysningen är iskall och bländar delvis besökarna då de går igenom rummet. Min tanke är att man ska uppleva detta som lite obehagligt och omtumlande.

\section{Sista rummet}

En lugn avslutning: Två interiörer, vardagsrummet och ateljén, båda oregelbundet inglasade, dominerar detta rum. Det finns naturligtvis bilder och texter på väggarna samt massor med Nell Waldens egen konst. Totala intrycket av detta rum är tänkt att vara ganska lugnt. Det finns även ett bord med stolar samt TV-video.

Vardagsrummet och ateljén är ljussatta så att alla föremål har korrekt belysning, utan att man för den skull tappar "hem- 
68 känslan«. Tekniken för detta var att först ljussätta miljöerna så att de blev trovärdiga, sedan plocka fram luxmätaren och korrigera alla farliga nivåer på föremålen.

\section{DET OSYNLIGA LJUSET}

Ljus i sig kan aldrig bli särskilt intressant för besökaren. Det måste vara utställningen som är det viktiga.

Men jag vet att en medveten utställningsljussättning kan tillföra upplevelsen och berättandet oerhört mycket, trots att ljuset självt saknar egentligt egenvärde.

Ljus kanske bäst fyller sina syften då det inte »syns«.

\section{SUMMARY}

\section{Lighting in museums and in theatres}

The author normally works with a theatre company. Together with a stage designer he has also assisted in the preparation of exhibitions and compares his experiences of lighting in the different settings. The general principles are the same, e.g. that our sense of light and dark is always determined by changes in the intensity of light and by its colouring. The basic difference lies in the fixed position of the audience in the theatre and the moving museum visitor added to which are strict norms governing the amount of light permitted to play on the various materials that make up museum objects with a view to counteracting deterioriation. However, if you want to use light for emphasis and to create an attractive and exciting atmosphere in an exhibition, you must be allowed to experiment for a while until the desired effect is achieved. Then the light can be reduced to accord with the rules valid for the individual object, while keeping the relative contrasts and shades.

As a case study he describes in detail how the general principles were applied in the lighting of one specific exhibition, presenting Nell Walden, an artist and well-known personality in the cultural life of Berlin in the 1920's. The exhibition was produced in 1986 in the municipal museum of Landskrona, where Nell Walden was born.

Light in itself is of no special interest for the museum visitor. The exhibition, its objects and messages, are the important things. Nevertheless the conscious and imaginative use of lighting can contribute immensely to better and more effective communication.

* Texten är en bearbetad version av en föreläsning $\mathrm{i}$ Holstebro i sept 1992.

Stefan Wiktorsson driver forretaget Ljusdesign i Gävle. Han svarade 1979-1994 for ljussättningen av 60 pjäsuppsättningar, de flesta for Skainska teatern $i$ Landskrona, Folkteatern i Gävle och Dalateatern, ofta i samarbete med regissören Peter Oscarsson och scenografen Peter Holm. Utom i Landskrona museum har han svarat för ljussättning av utställningar $i$ bl a Sjöhistoriska museet och Vasamuseet, Stockholm, samt det nyöppnade länsmuseum Västernorrland, Härnösand. Adr: S. Skeppsbron 4, S-802 80 Gävle Fax $+46-26513460$. 